\title{
The Levels of Predictors of Thrombotic Complications in Children with Congenital Heart Disease
}

\author{
Olga B. Gordeeva* (D), Vasiliy A. Lastovka, Rustam F. Tepaev \\ Federal State Autonomous Institution “National Medical Research Center of Children's Health” of the Ministry of Health of the \\ Russian Federation, Moscow, Russia \\ Email: ${ }^{*}$ obr@yandex.ru
}

How to cite this paper: Gordeeva, O.B., Lastovka, V.A. and Tepaev, R.F. (2019) The Levels of Predictors of Thrombotic Complications in Children with Congenital Heart Disease. Open Access Library Journal, 6: e5353.

https://doi.org/10.4236/oalib.1105353

Received: March 27, 2019

Accepted: May 24, 2019

Published: May 27, 2019

Copyright $\odot 2019$ by author(s) and Open Access Library Inc.

This work is licensed under the Creative Commons Attribution International License (CC BY 4.0).

http://creativecommons.org/licenses/by/4.0/

\section{(c) (i) Open Access}

\begin{abstract}
Thrombotic complications accompany surgical treatment, especially in children. Thrombosis is one of the actual problems of pediatrics. This problem is associated with severe complications, serious health problems in infant. This can contribute to increases of mortality in children with congenital heart diseases (CHD). In this article we discuss some aspects of thrombosis in the postoperative period of $\mathrm{CHD}$ in children with cardiopulmonary bypass (CPB). Current research shows us the parameters of plasma hemostasis which can be used as predictors of thrombotic complications in the postoperative period in children. According to our results, fibrin monomer and von Willebrand factor may be recommended for use as predictors of thrombosis in children with CHD.
\end{abstract}

\section{Subject Areas}

Pediatrics

\section{Keywords}

Hemostasis, Fibrin Monomer, Von Willebrand Factor, Children, Thrombosis

\section{Introduction}

The problems of thrombotic complications and bleeding are important questions in pediatrics, because coagulation imbalance occurs in children very often. $\mathrm{CBP}$ is an integral part of open heart surgery, which may contribute to thrombotic complications and bleedings. As known, platelet level decreases to 50\% from baseline in the first minutes of CPB [1]. Reducing the concentration of plasma factors V, VII, IX, X and XIII, fibrinogen, prothrombin, antithrombin, 
plasminogen and antiplasmin significantly increase the risk of hemorrhagic and thrombotic complications. According to some researchers, bleeding in the postoperative period (with CBP) is- $8.4 \%$ in structure of complications in children [2]. The development of hemocoagulation imbalance can increase mortality and cost of treatment.

\section{The Purpose and Objectives}

We present some indicators of hemostasis, which may be us as predictors of thrombotic complications in children after heart surgery in the first year of life.

\section{Materials and Methods}

We examined 26 children aged 2 days to 12 months. Median (Me) of age was 5.5 months. All patients received surgical treatment of CHD with CPB. Girls were -7 (27\%) and boys were-19 (73\%). The ratio of girls/boys is 1:2.7.

Some hemostasis parameters: fibrinogen concentration, activated partial thromboplastin time (APTT), thrombin time (TV), prothrombin time (PV), the levels of fibrin monomers (FM) and von Willebrand factor ( $\mathrm{vWf}$ ) were investigated in citrate plasmaat automatic analyzer of hemostasis (Stago, France).

All patients were divided into 2 groups. The first group included children without thrombotic events at the clinic $(n=22)$; the second group included children with thrombotic events $(n-4)$. The observation included three points of study: 1 point-before the operation; 2 point-the first day after surgery operation; 3 point-3rd days after surgery operation. A statistical program (Statistica 6.0 software package (StatSoft Inc., Tulsa, Ok, USA) was used in this study. We have been used the Mann-Whitney test. The statistically significant differences were considered $\mathrm{p} \leq 0.05$.

\section{Results}

1) We did not detect hemorrhagic complications in our patients.

2) Thrombotic complications were observed in four (15.4\%) children.

3) One case was fatal. There are three cerebral thrombosis $11.5 \%$ in the second group. In one case we observed thrombus in the apex of the left ventricle (3.8\%).

4) We did not detect hemostatic disorders in the study of screening parameters: fibrinogen concentration, activated partial thromboplastin time (APTT), thrombin time (TV), prothrombin time (PV).

5) We identified statistically significant differences in levels of fibrin monomer in both groups. Its level was within the reference interval before the operation in the first group. The median (Me) at the first point, made up $8.21 \mu \mathrm{g} / \mathrm{ml}$; at the second point-Me was of $13.78 \mu \mathrm{g} / \mathrm{ml}$; and at the third point Me was-of $8.72 \mu \mathrm{g} / \mathrm{ml}$ (reference values of $2.46-$ of $11.96 \mu \mathrm{g} / \mathrm{ml})(\mathrm{P}<0.05)$. We detected a slight excess of FM level at the second point in the first group only. The level of FM returned to the preoperative state on the third day in the first group.

The median (Me) of FM were: $78.33 \mu \mathrm{g} / \mathrm{ml}$ at the first point; $37.15 \mu \mathrm{g} / \mathrm{ml}$ and 
$79.44 \mu \mathrm{g} / \mathrm{ml}$ at the second and third points accordingly. The levels of FM exceeded of reference values at all points in the second group. In this case the level of FM was significantly higher in the third point than in the 1st and 2nd points. As can be seen from Figure 1, before the surgery its level was much higher than the reference values and the level at the second point.

The level of vWf in the second group significantly exceeded (22\%) the level of vWf at first group. We discovered that activity of vWf was from $71 \%$ to $290 \%$ ( $\mathrm{Me}-105 \%)$ in the first group. In the second group the activity of vWf made $100 \%-228 \%(\mathrm{Me}-128 \%)$. Reference range of vWf is: $50 \%-120 \%$. It should be noted than activity of $\mathrm{vWf}$ was the highest at the second point in both groups.

The activity of vWf decreased in the 3-rd point at the 1-st group of patients, but in the 2-nd group the activity remained at a high level.

Figure 2 shows the dynamics of the von Willebrand factor. The activity of the vWf was significantly exceeded (almost 85 percent) in the 2 nd group in the 1-st point by comparison of patients of the first group.

\section{Resume}

1) The activity of von Willebrand factor was within reference limits $(50 \%$ $120 \%$ ) before the surgery in the first group. Median was $104 \%$. This value increased to $292 \%$ in the second point of observation and the level of vWf decreased to $170 \%$ in the third point of observation.

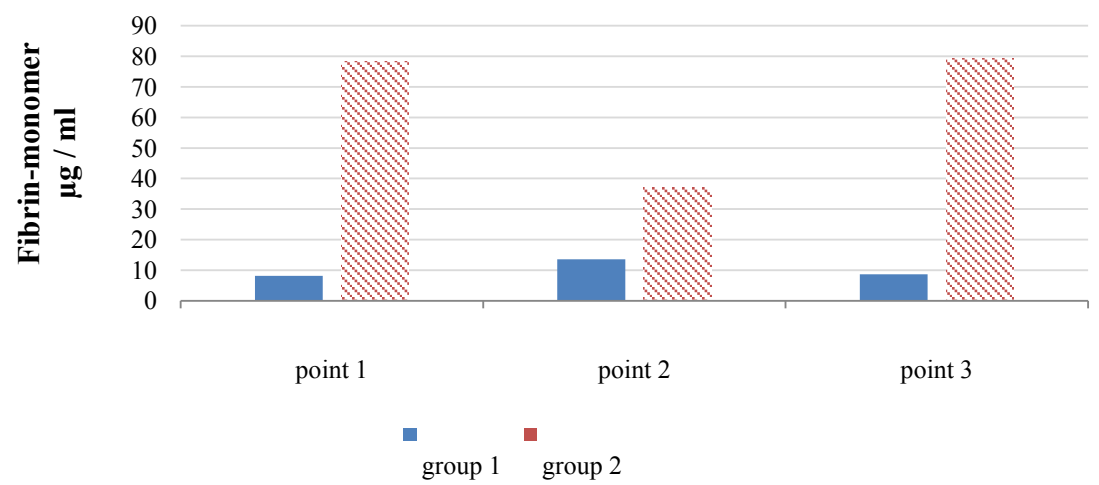

Figure 1. The level of fibrin monomers $(\mu \mathrm{g} / \mathrm{ml})$ at 3 points of the study.

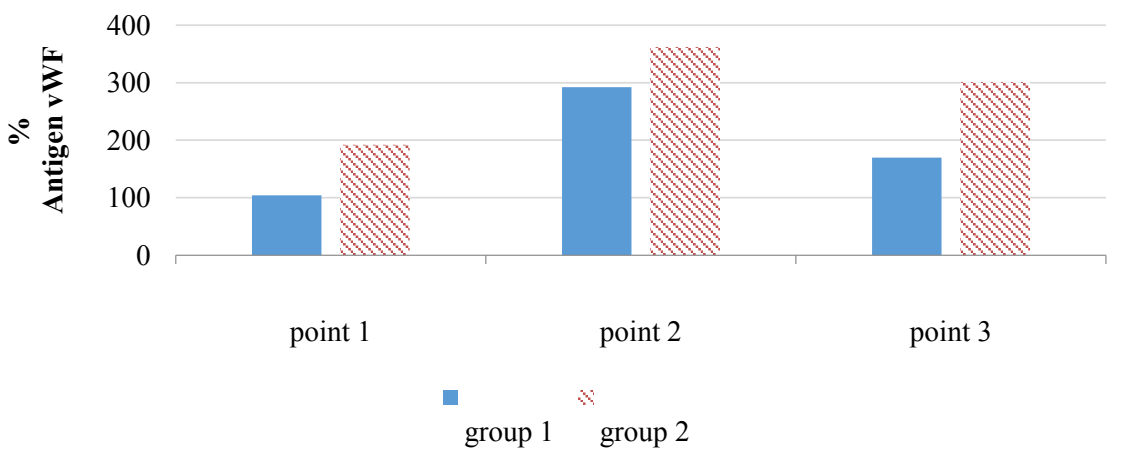

Figure 2. Level of vWF at three points in both groups. 
2) We have established some increase in activity of von Willebrand factor in the second group. Its activity was higher than the reference limits at each point of observation and significantly higher than in the first group ( $\mathrm{p} \leq 0.05)$. Medians were $192 \%, 362 \%$ and $301 \%$ at the 1 st, 2 nd and 3rd points respectively.

3) A high level of von Willebrand factor can be considered as a marker of endothelial dysfunction. Some scientists used in their work the level of the vWf as a marker of damage to the vascular endothelium. Its parameter may be associated with the occurrence of thrombosis in children with $\mathrm{CHD}$ after heart surgery with CPB [3].

4) According to some works the FM level increase can be considered as a high risk marker of cardiovascular complications, mortality from cardiovascular diseases and increased risk of overall mortality in patients with atrial fibrillation [4].

\section{Conclusions}

The elevated levels of FM and von Willebrand factor can be used as markers of thrombotic complications associated with the use of cardiopulmonary bypass at heart surgery, especially in children in the first year of life.

The high level of von Willebrand factor in the plasma is a pathophysiological marker of endothelial dysfunction.

The determination of FM level and of $\mathrm{vWf}$ can be used as prognostic markers of thrombotic complications in patients with $\mathrm{CHD}$ using $\mathrm{CPB}$ in heart surgery.

\section{Conflicts of Interest}

The authors declare no conflicts of interest regarding the publication of this paper.

\section{References}

[1] Sniecinski, R.M. and Chandler, W.L. (2011) Activation of the Hemostatic System during Cardiopulmonary Bypass. Anesthesia \& Analgesia, 113, 1319-1333.

https://doi.org/10.1213/ane.0b013e3182354b7e

[2] Gu, Y.J., Boonstra, P.W., Graaff, R., Rijnsburger, A.A., Mungroop, H. and Van Oeveren, W. (2000) Pressure Drop, Shear Stress, and Activation of Leukocytes during Cardiopulmonary Bypass: A Comparison between Hollow Fiber and Flat Sheet Membrane Oxygenators. Artificial Organs, 24, 43-48. https://doi.org/10.1046/j.1525-1594.2000.06351.x

[3] Shahidi, M. (2017) Thrombosis and von Willebrand Factor. Advances in Experimental Medicine and Biology, 906, 285-306.

[4] Rivera-Caravaca, J.M., Roldán, V., Romera, M., Asunción, M., Pastor, E., Valdés, M., Lip, G.Y.H., Vicente, V. and Marín, F. (2018) Soluble Fibrin Monomer Complex and Prediction of Cardiovascular Events in Atrial Fibrillation: The Observational Murcia Atrial Fibrillation Project. Journal of General Internal Medicine, 33, 847-854. https://doi.org/10.1007/s11606-017-4279-4 